\title{
The 'Nightmare' of Wrong Level in Spine Surgery: Is Minimally Invasive Spine Technique More Forgiving?
}

\author{
Arvind Gopalrao Kulkarni, Sudhir Gupta, Vishwanath M. Patil \\ Consultant Spine Surgeon, Mumbai Spine Scoliosis and Disc Replacement Centre, Bombay Hospital \& Medical Research Centre, \\ Mumbai, India
}

Corresponding Author: Arvind Gopalrao Kulkarni, MD, MS, FCPS, SICOT

Consultant Spine Surgeon, Mumbai Spine Scoliosis and Disc Replacement Centre, 2nd floor Room No. 206 New Wing, Bombay Hospital \& Medical Research Centre, 12, New Marine Lines, Mumbai400020, India

Tel: $+91-9892875490$ Fax: +91-22-22080871

E-mail: drarvindspines@gmail.com

Received: April 28, 2017 Revised: May 29, 2017 Accepted: May 31, 2017
Objective: Operating on a wrong level is a nightmare for every surgeon, which has devastating consequences for the patient as well as the surgeon and has potential for serious medical, personal and legal repercussions. There is limited literature of Wrong Level Spine Surgery (WLSS) in Minimally Invasive Spine Surgery (MISS). The aim of the study is to evaluate the incidence of WLSS in MISS using tubular retractors. Methods: The study included a retrospective review of prospectively collected data of all MIS surgeries utilizing tubular retractors during the period extending from January 2007 to December 2014. The surgeries included Micro-Endoscopic Discectomies, Micro-Endoscopic Decompression surgeries for lumbar canal stenosis and Minimal Invasive Trans-Foraminal Lumbar Interbody Fusion (MI-TLIF) surgeries. The surgeries involved docking of the tubular retractor at the level of interest under fluoroscopic guidance. Surgical charts as well as clinical and imaging followup data were analyzed. The incidence of WLSS was analyzed. Results: There were 1,043 surgeries in all in the study period. There were 393 discectomies, 370 decompressions and $280 \mathrm{Ml}$-TLIF surgeries. There were no wrong level surgeries in the entire series. There were two $(0.19 \%)$ wrong side tube dockings which were subsequently rectified during surgery. No clinical complications were seen. The results were reviewed in light of a meta-analysis of current literature available on WLSS in open and MISS. The results were consistent with the present literature in demonstrating a decreased incidence of WLSS with MISS. Conclusion: The docking of the tubular retractor under fluoroscopic guidance offers an advantage of preventing WLSS. This is an additional benefit of MISS using tubular retractors.

Key Words: Minimally invasive spine surgery, Wrong level surgery, Incidence

\section{INTRODUCTION}

Among the peri-operative incidents, operating on a wrong level/site is a nightmare for every surgeon. The term 'wrong-site surgery' was devised as a concept to include events such as operating on the wrong person, the wrong organ or limb, or the wrong vertebral level ${ }^{1)}$. Wrong-level indicates that a level other than the level of the disorder is operated ${ }^{2)}$. Wrong Level Spine Surgery (WLSS) is a unique pitfall and it fails to resolve the pathologic abnormality, clinical symptoms and has profound medical, legal, social and emotional implications ${ }^{3,4)}$. WLSS is significantly underreported ${ }^{5}$, as per Joint Commission's (JCAHO) report, wrong-patient, wrong-site, or wrong-procedure events were the most common sentinel events amounting to $13 \%$ of all the events (928 of 6,994 events) between 2004 to 20124).

Groff et al. ${ }^{6}$ ) in their survey on members of American Association of Neurological Surgeons had concluded that there is a substantial heterogenecity in approaches among different surgeons to localize the desired surgical level. They also concluded that presently there is no universally implemented standard in place to reduce the incidence of wrong-level surgery, and the existing safety protocols are not decreasing the occurrence of wrong-level surgery to the extent as thought.

There has been an increasing interest in Minimally Invasive Spine Surgery (MISS) in recent times. There are obvious advantages of MISS over open surgery which include less tissue trauma, less blood loss, low rate of peri-operative complications, minimal post operative morbidity, decreased hospital stay and eventually $\operatorname{cost}^{7}$. In view of current literature the study was done to assess the association of MISS and WLSS.

\section{MATERIALS AND METHODS}

The study included a retrospective review of prospectively 
collected data of all MIS surgeries commonly performed in our department of varied etiologies, utilizing tubular retractors during the period extending from January 2007 to December 2014. The surgeries included Micro-Endoscopic Discectomies, MicroEndoscopic Decompression for lumbar canal stenosis and Minimal Invasive Trans-Foraminal Lumbar Inter-body Fusion (MI-TLIF) surgeries. Microendoscopic Discectomy was done using 16/18 mm diameter tubes whereas Microendoscopic Decompression was performed with $18 \mathrm{~mm}$ tubes; MI-TLIF was done using $22 \mathrm{~mm}$

Table 1. Total number and type of surgeries in the study

\begin{tabular}{lc}
\hline \hline Surgery performed & Number (n) \\
\hline Microendoscopic discectomy & 393 \\
Microendosopic decompression & 370 \\
Minimally invasive - TLIF & 280 \\
Total & 1,043 \\
\hline
\end{tabular}

tubes. All the procedures involved similar techniques of docking of the tubular retractor at the level of interest under fluoroscopic guidance and performing the respective surgeries ${ }^{7}$. Surgical charts as well as clinical and imaging follow-up data were analysed. Imaging involved radiographs, computed tomography scans and magnetic resonance imaging scans done as per the need. All the patients in whom instrumentation was done were followed up with a postoperative radiograph. The incidence of WLSS was analysed. The results were reviewed in the light of an analysis of current literature available on WLSS in Open and MISS.

\section{RESULTS}

A total of 1,043 MIS Surgeries of varied etiologies were included in the study period (Table 1). There were no wrong level surgeries in the entire series. There were two $(0.19 \%)$ wrong side tube dockings which were subsequently rectified during

Table 2. Meta-analysis of Literature on WLSS in Open and MISS

\begin{tabular}{|c|c|c|c|c|}
\hline Author/s & Number (n) & Diagnosis & Procedure & Wrong level frequency \\
\hline Williams RW & 530 & Lumbar disc herniations & Microdiscectomy & $3(0.6 \%)$ \\
\hline Eie et al. ${ }^{9}$ & 943 & Lumbar disc herniations & $\begin{array}{l}\text { Lumbar disc surgery with or } \\
\text { without fusion }\end{array}$ & $20(2.1 \%)$ \\
\hline Ruggieri et al. ${ }^{10)}$ & 872 & Lumbar disc herniations & Discectomy & $7(0.8 \%)$ \\
\hline Barrlos et al..$^{11)}$ & 150 & Lumbar disc herniations & $\begin{array}{l}\text { Microdiscectomy (75), } \\
\text { Discectomy (75) }\end{array}$ & $5(3.3 \%)$ \\
\hline Goodkin and Laska ${ }^{12)}$ & 21 & Lumbar disc herniations & $\begin{array}{l}\text { Discectomy (7), } \\
\text { Microdiscectomy (1), } \\
\text { Laminectomy (15) }\end{array}$ & $\begin{array}{l}1(14.3 \%) \\
\text { (wrong level exposure) }\end{array}$ \\
\hline Ebraheim et al. ${ }^{13)}$ & 80 & Varied Etiologies & $\begin{array}{l}\text { Posterolateral } \\
\text { fusion without } \\
\text { instrumentation }\end{array}$ & $4(5 \%)$ \\
\hline Ammerman et al. ${ }^{14)}$ & 100 & Lumbar disc herniation & $\begin{array}{l}\text { Standard } \\
\text { Discectomy }\end{array}$ & $15(15 \%)$ \\
\hline Jhawar et al. ${ }^{15)}$ & 7,344 cases & $\begin{array}{l}\text { Disc degeneration and } \\
\text { disc herniation }\end{array}$ & $\begin{array}{l}\text { Lumbar discectomy }(4,695) \text {, } \\
\text { Cervical discectomy }(2,649)\end{array}$ & $\begin{array}{l}8(0.01 \%) \\
\text { Lumbar- } 6(0.1 \%), \\
\text { Cervical- } 2(0.1 \%)\end{array}$ \\
\hline K N Acharya et al. ${ }^{16)}$ & 273 & Disc herniation & $\begin{array}{l}259 \text { Primary discectomy and } 14 \\
\text { revision surgeries }\end{array}$ & $1(0.3 \%)$ \\
\hline Mody et al. ${ }^{17)}$ & $\begin{array}{l}\text { 1,300,000 spine } \\
\text { procedures }\end{array}$ & $\begin{array}{l}\text { Disc degeneration and } \\
\text { disc herniation }\end{array}$ & & $418(0.03 \%)$ \\
\hline Irace and Corona ${ }^{18)}$ & 818 & $\begin{array}{l}\text { Primary lumbar disc } \\
\text { herniations (765), } \\
\text { recurring lumbar disc } \\
\text { herniations (53) }\end{array}$ & $\begin{array}{l}\text { Single-level lumbar } \\
\text { microdiscectomy }\end{array}$ & $\begin{array}{l}\text { 1- }(0.1 \%) \\
\text { (Wrong-level exposure) }\end{array}$ \\
\hline Matsumoto $\mathrm{M}$ et al. ${ }^{19)}$ & $\begin{array}{l}\text { 6,239 spinal } \\
\text { endoscopic } \\
\text { surgeries }\end{array}$ & & $\begin{array}{l}\text { 4,336 cases of microendoscopic } \\
\text { discectomy (MED), 1,273 cases } \\
\text { of microendoscopic } \\
\text { laminectomy and } 379 \text { fusions }\end{array}$ & $7(0.01 \%)$ \\
\hline Ebata et al. ${ }^{20)}$ & 611 & $\begin{array}{l}\text { Lumbar disc herniation, } \\
\text { lumbar spinal stenosis, } \\
\text { degen spondylolishesis, } \\
\text { facet joint cysts }\end{array}$ & Microendoscopic decompression & $3(0.49 \%)$ \\
\hline
\end{tabular}


surgery. The absence of frank disc herniation led to fluoroscopic control in this case, and the corrective surgery was done from the contra-lateral side. This kind of contra-lateral decompression/ discectomy can be performed with the tubular retractors. No clinical complications were seen. The results were reviewed in light of a meta-analysis of current literature available on WLSS in open and MISS (Table 2). The results were consistent with the present literature in demonstrating a decreased incidence of WLSS with MISS.

\section{DISCUSSION}

The term Never Event is currently used to refer those operations performed on the incorrect side or at the wrong level, with the later particularly referring to spinal surgery ${ }^{21)}$. Wrong level spine surgery occurs when a surgeon performs decompression, resection or reconstructive procedure on an unintended anatomic location along the spinal axis ${ }^{22)}$. It is an unique problem in spinal surgery and has profound medical, legal and social repercussions. From a Clinical stand point, the pathologic process and patient's symptomatology are not addressed in the setting of WLSS.

The incidence of WLSS in open spine surgeries worldwide varies from 0.1 to $15 \%{ }^{8-17)}$. There is heterogeneity of the data available and the incidence is expected to be higher than has been reported. Mody et al. ${ }^{17)}$ in his questionnaire study found high prevelance of wrong level surgeries among spine surgeons with nearly $50 \%$ of surgeons performing atleast one WLSS during their career. The overall strength of the data available to establish the risk factors for WLSS has been rated as 'Low'.

A number of universally accepted protocols have been established and practised for reducing the incidence of WLSS. These protocols varies among different hospital and among surgeons. The 'Sign Through Your Initials' by the Canadian Orthopaedic Association ${ }^{24)}$, the 'Sign Your Site' programme by American Orthopaedic Surgeons, the Sign, Mark and X-ray (SMax) programme by North American Spine Society ${ }^{25)}$, and the Universal Protocol for Preventing Wrong Site, Wrong Procedure, Wrong Person Surgery by the Joint Commission on the Accreditation of Healthcare Organizations $(\mathrm{JCAHO})^{26)}$ are among the commonly recognized protocols.

The most trusted methodology is to obtain an intra-operative radiograph check to exact the vertebral level by marking a fixed anatomical structure with metallic marker ${ }^{4}$. However, obtaining intra-operative radiograph does not guarantee the correct level. Congenital variations, inadequate radiological exposure or incorrect identification of the level, inadequate radiological visualisation because of large body size or inadequate size of operating table, and failure to recognise the absence of an expected lesion at the operative.

Level, can all lead to misinterpretation of the radiological image. Optimum pre-operative planning is an integral part of reducing the incidence of WLSS in MISS. Several other methods have been proposed to identify the site of operation, including intra-operative CT, spinal neuronavigation, transligamentous ultrasound, and longitudinal surface markers filled with halibut liver oil ${ }^{17)}$.

The ongoing efforts to reduce the incidence of WLSS are credited with widespread use of Minimally Invasive Spine Surgery. The incidence of WLSS is $0.09-3.3 \%{ }^{18-20)}$. The MIS surgeries using tubular retractors involves operating through tubular ports. The tubular ports land over the lamina of interest following progressive dilatation of the intermuscular plane. The inter-muscular dilatation is performed using a series of dilators of increasing diameter that are passed over a guide wire. The passage of the guide wire is central to localization of the operating level following which the dilators are passed. All these steps are performed sequentially under C-arm guidance (Fig. 1). Hence there are ample opportunities for the operating surgeon to not only confirm the localization of the correct level but also cross-check the same. The sequential series of steps initially starting with the guide-wire and then the dilators and finally the tubular port, being $\mathrm{C}$-arm guided provide serial check-points to assure that the correct level is localized and operated upon. These radiographs are compared with the pre-operative films. In the present study the incidence is Zero and this can be attributed to serial radiographic guidance which is unique in MISS (serial check points from guide wire to final tube) to dock the tube.

To authors knowledge this is the maximum number of MISS cases studied at a single centre by a single surgeon. There
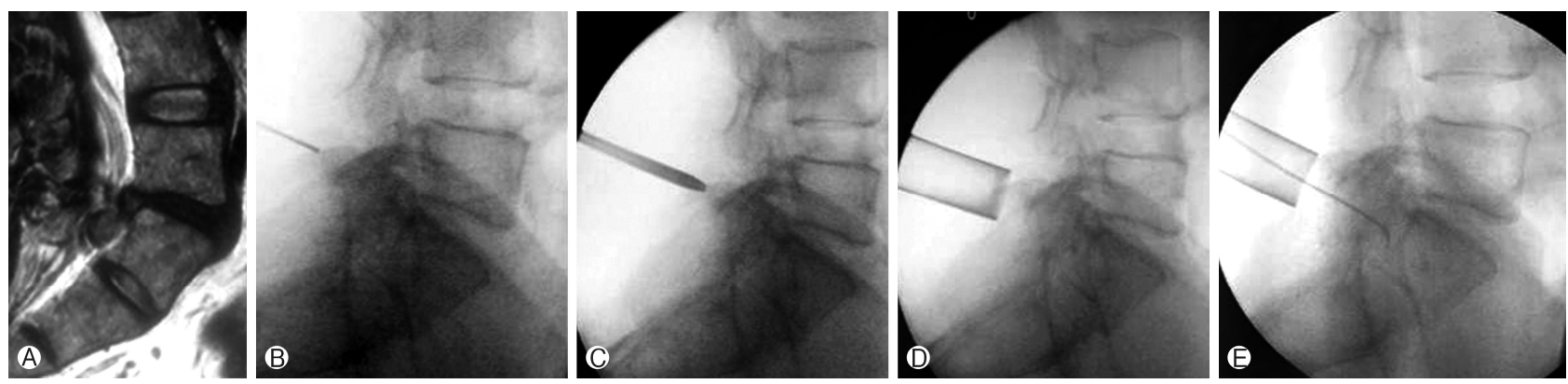

Fig. 1. A Pre-operative MRI showing Sacralisation of last lumbar vertebra, (B) A spinal needle is first inserted at desired level (C) Progressive dilators are passed, (D) Radiograph after docking the tube, (E) Penfield at the pedicle showing satisfactory decompression. 
were two cases of wrong side tubular docking but it did not result in additional incision/exposure as the contralateral decompression is easily done using tubular retractors by 'over the top' technique ${ }^{7,23)}$. Using a unilateral tubular portal a bilateral bony and ligamentous decompression can be achieved under the midline, thereby preserving the supraspinous-interspinous ligaments and contralateral musculature. Even if the tube is docked on the wrong side it is possible to decompress or perform a discectomy on the opposite side without any additional incision/exposure. It is our protocol to obtain radiographs postoperatively in all instrumentation cases.

The present study is not without limitations. There is relatively increased exposure to radiation in confirming levels at each step in MIS surgeries. Use of better planned pre-operative template and obtaining selected intra-operative radiographs will reduce the exposure to radiation.

\section{CONCLUSION}

It can be stated that the spine surgeon is the only healthcare provider with access to all the information necessary to identify the correct spinal segment at the time of surgery. Inherent technique of MISS using tubular retractors involves serial checkpoints and final confirmation of parking the tubular retractor on a lateral image intensifier image. Hence the risk of exploring and operating on wrong level is unlikely. This is an added advantage of tubular retractors along with other benefits such as minimal soft tissue trauma, early mobility, less blood loss, better cosmesis etc.

\section{KEY POINTS}

Wrong site surgery fails to improve the patient's symptoms and has medical, emotional, social, and legal implications.

The spine surgeon is the only healthcare provider with access to all the information necessary to identify the correct spinal segment at the time of surgery.

Inherent technique of MISS using tubular retractors involves final confirmation of parking the tubular retractor on a lateral image intensifier image.

Added advantage of tubular retractors along with other benefits such as minimal soft tissue trauma, early mobility, less blood loss, better cosmesis etc.

\section{REFERENCES}

1. Wong DA, Herndon JH, Canale ST, et al: Medical errors in orthopaedics: results of an AAOS member survey. J Bone Joint Surg Am 91-A:547-557, 2009

2. Devine J, Chutkan N, Norvell DC, Dettori JR: Avoiding wrong site surgery: a systematic review. Spine (Phila Pa 1976) 35:28-36, 2010

3. U. G. Longo, M. Loppini, G. Romeo, N. Maffulli, V. Denaro: Errors of level in spinal surgery - An evidence-based systematic review. J Bone Joint Surg Br 94-B:1546-1550, 2012
4. Mark A. Palumbo, Aaron J. Bianco, Sean Esmende, Alan H. Daniels: Wrong-site Spine Surgery. J Am Acad Orthop Surg 21: 312-320, 2013

5. Todd Francis and Edward Benzel: Wrong Level Spine Surgery: A Perspective. World Neurosurgery 79(3/4):451-452, 2013

6. Michael W. Groff, Joshua E. Heller, Eric A. Potts, Praveen V. Mummaneni et al: Survey-Based Study of Wrong-Level Lumbar Spine Surgery: The Scope of the Problem and Current Practices in Place to Help Avoid These Errors. World Neurosurg 79( 3/4):585-592, 2013

7. Podichetty VK, Spears J, Isaacs RE, Booher J, Biscup RS: Complications associated with minimally invasive decompression for lumbar spinal stenosis. J Spinal Disord Tech 19(3):161-166, 2006

8. Williams RW: Microlumbar discectomy: a conservative surgical approach to the virgin herniated lumbar disc. Spine (Phila Pa 1976) 3:175-182, 1978

9. Eie N, Solgaard T, Kleppe H: The knee-elbow position in lumbar disc surgery: A review of complications. Spine (Phila Pa 1976) 8:897-900, 1983

10. Ruggieri F, Specchia L, Sabalat S, et al: Lumbar disc herniation: diagnosis, surgical treatment, recurrence: a review of 872 operated cases. Ital J Orthop Traumatol 14:15-22, 1988

11. Barrios C, Ahmed M, Arrótegui J, Björnsson A, Gillström P: Microsurgery versus standard removal of the herniated lumbar disc: a 3-year comparison in 150 cases. Acta Orthop Scand 6: 399-403, 1990

12. Goodkin R, Laska LL: Vascular and visceral injuries associated with lumbar disc surgery: medicolegal implications. Surg Neuro 49:358-370, 1998

13. Ebraheim NA, Inzerillo C, Xu R: Are anatomic landmarks reliable in determination of fusion level in posterolateral lumbar fusion? Spine (Phila Pa 1976) 24:973-974, 1999

14. Ammerman JM, Ammerman MD, Dambrosia J, Ammerman BJ: A prospective evaluation of the role for intraoperative X-ray in lumbar discectomy. Predictors of incorrect level exposure. Surg Neurol 66:470-473, 2006

15. Jhawar BS, Mitsis D, Duggal N: Wrong-sided and wrong-level neurosurgery: a national survey. J Neurosurg Spine 7:467-472, 2007

16. KN Acharya, TS Senthil Nathan, J Renjit Kumar, K Venugopal Menon: Primary and revision lumbar discectomy: A three-year review from one center. IJO 42(2):178-181, 2008

17. Milan G. Mody, Ali Nourbakhsh, Daniel L. Stahl, Mark Gibbs et al: The Prevalence of Wrong Level Surgery Among Spine Surgeons. SPINE 33(2):194-198, 2008

18. Irace C, Corona C: How to avoid wrong-level and wrong-side errors in lumbar microdiscectomy. J Neurosurg Spine 12:660665,2010

19. Matsumoto M, Hasegawa T, Ito M, Aizawa T, et al: Incidence of complications associated with spinal endoscopic surgery: nationwide survey in 2007 by the Committee on Spinal Endoscopic Surgical Skill Qualification of Japanese Orthopaedic Association. J Orthop Sci 15(1):92-96, 2010

20. Shigeto Ebata, Hirokazu Sato, Hisaya Orii, Shinichi Sasaki, Tetsuro Ohba, Hirotaka Haro: Risk management in posterior spinal endoscopic surgery in lumbar diseases. J Orthop Sci 18:369-373, 2013

21. Michaels RK, Makary MA, Dahab Y, Frassica FJ, Heitmiller 
E, Rowen LC, et al: Achieving the National Quality Forum's "Never Events": prevention of wrong site, wrong procedure, and wrong patient operations. Ann Surg 245:526-532, 2007

22. Mark A.Palumbo, Aaron J Bianco, Sean Esmende, Alan H Daniels: Wrong-site spine surgery. J Am Acad Orthop Surg 21:312320, 2013

23. Ikuta K, Arima J, Tanaka T, Oga M, et al: Short-term results of microendoscopic posterior decompression for lumbar spinal stenosis. Technical note. J Neurosurg Spine 2(5):624-633, 2005

24. Canadian Orthopaedic Association Committee on Practice and Economics. Position paper on wrong sided surgery in orthopae- dics. Winnipeg, Manitoba: Canadian Orthopaedic Association 1994

25. American Academy of Orthopaedic Surgeons: Advisory statement wrong-site surgery. Rosemont, IL: American Academy of Orthopaedic Surgeons 2000

26. Emily M Lindley, Sergiu Botolin, Evalina L Burger and Vikas V Patel: Unusual spine anatomy contributing to wrong level spine surgery: a case report and recommendations for decreasing the risk of preventable 'never events'. Patient Safety in Surgery 5:33, 2011 